\title{
O VALOR DA TERAPIA COMUNITARIA INTEGRATIVA (TCI) NO BRASIL E NO MUNDO: POSSIBILIDADES, IMPACTOS E PERSPECTIVAS
}

\section{EL VALOR DE LA TERAPIA COMUNITARIA INTEGRATIVA (TIC) EN BRASIL Y EL MUNDO: POSIBILIDADES, IMPACTOS Y PERSPECTIVAS}

\section{THE VALUE OF INTEGRATIVE COMMUNITY THERAPY (ICT) IN BRAZIL AND THE WORLD: POSSIBILITIES, IMPACTS AND PERSPECTIVES}

\author{
Anamélia Lins e SILVA FRANCO ${ }^{1}$ \\ Milene Zanoni da SILVA ${ }^{2}$ \\ Josefa Emilia LOPES RUIZ ${ }^{3}$ \\ Morgana MURCIA ${ }^{4}$ \\ Taisa Borges DE SOUZA ${ }^{5}$ \\ Luci Regina MUZZETI ${ }^{6}$ \\ Terapeutas Comunitárias Integrativos \\ Organizadoras
}

Esse dossiê tem a honra de divulgar reflexões, saberes e conhecimentos acadêmicos, sobre a Terapia Comunitária Integrativa no Brasil e no exterior. Seu criador Prof. D.r Adalberto de Paula Barreto, de Fortaleza-CE, psiquiatra, antropólogo e teólogo sensibilizado pelas Dores da Alma, preocupado com a medicalização excessiva sem muitas mudanças e crente na força da comunidade, cria uma metodologia particular com estrutura simples e profunda, fortalecedora de vínculos afetivos e promotora do alivio de sofrimentos, onde inclui bases teóricas do pensamento sistêmico, da antropologia cultural, da teoria da comunicação humana,

${ }^{1}$ Universidade Federal da Bahia (UFBA), Salvador - BA - Brasil. Professora Associada I do Instituto de Humanidades Artes e Ciências Professor Milton Santos. Doutorado em Saúde Coletiva (UFBA). ORCID: https://orcid.org/0000-0001-9651-7992.E-mail: anamelialins@gmail.com

${ }^{2}$ Universidade Federal do Paraná (UFPR), Curitiba - PR - Brasil. Docente Permanente do Programa de PósGraduação em Saúde Coletiva. Doutorado em Saúde Coletiva (UEL). Membro da Associação Brasileira de Terapia Comunitária Integrativa (ABRATECOM). ORCID: https://orcid.org/0000-0002-1177-9668. E-mail: milenezanoni@gmail.com

${ }^{3}$ Universidade Estadual Paulista (UNESP), Araraquara - SP - Brasil. Psicóloga da Unidade Auxiliar do Centro de Pesquisas da Infância e da Adolescência (CENPE). Graduada no curso de Psicologia (USP). Membro da Associação Brasileira de Terapia Comunitária Integrativa (ABRATECOM). ORCID: https://orcid.org/0000-00028636-537. E-mail: josefa.ruiz@unesp.br

${ }^{4}$ Universidade Estadual Paulista (UNESP), Araraquara - SP - Brasil. Fonoaudióloga no Centro de Pesquisas da Infância e da Adolescência - CENPE/UNESP. Especialista em Psicopedagogia (UNICEP). ORCID: https://orcid.org/0000-0003-0704-1086. E-mail: morgana.murcia@unesp.br

${ }^{5}$ Universidade Estadual Paulista (UNESP), Araraquara - SP - Brasil. Psicólogo da Universidade Estadual Paulista. Especialização em Terapia Familiar e de Casais (PUC/SP). Membro de corpo editorial da Revista Temas em Educação e Saúde. ORCID: https://orcid.org/0000-0001-5197-2588. E-mail: taisa.borges@unesp.br

${ }^{6}$ Universidade Estadual Paulista (UNESP), Araraquara - SP - Brasil. Professora Livre Docente do Departamento de Didática. Doutorado em Educação (UFSCAR). ORCID: https://orcid.org/0000-0002-6808-2490. E-mail: luci.muzzeti@unesp.br 
da pedagogia de Paulo Freire, da resiliência, dos elementos culturais e o saber popular. A TCI é genuinamente brasileira, considerada uma abordagem psicossocial avançada pelo Ministério da Saúde, uma prática terapêutica coletiva que envolve os membros da comunidade numa atividade de construção de redes sociais solidárias, construção de vínculos e promoção de qualidade de vida. Está inserida na Política Nacional de Práticas Integrativas e Complementares (PNPIC) desde 2017 e presente em vários países; França, Portugal, Suíça, Alemanha, Ucrânia, Haiti, Kurdistan (Curdistão), Itália, Tailândia, Marrocos, Estados Unidos, RDC (República Democrática do Congo) e acabamos de pousar na tribo Bamilequês da República dos Camarões. Na América Latina estamos presentes; Brasil, Argentina, Bolívia, Chile, Equador, México, Peru, República Dominicana e Uruguai (ABRATECOM, 2020), atuando em diversas áreas: saúde, educação, assistência social, setores do poder judiciário, presídios, comunidades, associações e setor privado.

A TCI e a Política Nacional de Práticas Integrativas e Complementares em Saúde (PNPICS), um lugar de pertencimento!

A Terapia Comunitária Integrativa é uma prática integrativa brasileira!

Essa frase é proferida com certa frequência, mas o que importa é realmente o que significa. O Brasil desde 2006 possui a Política Nacional de Práticas Integrativas e Complementares em Saúde (PNPICS). Essa Política faz parte do conjunto de políticas que orientam as ações do Sistema Único de Saúde (SUS). A PNPICS foi criada porque os países signatários da Organização Mundial da Saúde foram convocados a oferecer outras medicinas além da alopatia, a medicina comumente chamada de biomedicina, a medicina químicomecanicista.

Então, a PNPICS possibilita que os usuários do SUS tenham acesso a possibilidade de escolher outros modos de prevenir e tratar de sua saúde. Isso já era frequente no Brasil, mas não era uma oportunidade para todos, mas somente para quem podia pagar as consultas e os tratamentos. Como também, profissionais de saúde que tinham formações em outros modos de cuidar além da biomedicina muitas vezes não eram apoiados, reconhecidos por seus gestores. A PNPICS é uma estratégia de democratização das práticas em saúde.

Atualmente, estão nomeadas na PNPICS quatro medicinas ou racionalidades médicas que são: a Medicina Aurvédica, a Medicina Tradicional Chinesa/Acupuntura, a Homeopatia e a Antroposofia. Estas são racionalidades médicas porque tem modos próprios de entender a fisiologia, a anatomia, o raciocínio clínico-diagnóstico, a terapêutica, a visão de mundo. Estas racionalidades possuem ações além da prática médica e envolvem a ação de outros profissionais 
de saúde. A PNPICS também possui 29 recursos terapêuticos listados, entre estes está a Terapia Comunitária Integrativa (TCI).

É importante entender porque essas outras formas de prevenção e tratamentos são consideradas complementares e integrativas. Olhando para história recente das práticas em saúde, sabemos que no final da década de sessenta ocorreu o movimento contracultural que questionava principalmente o modo de vida ocidental e capitalista, esse movimento incentiva a adoção de práticas alternativas em saúde. Isso significa dizer, modos de prevenir e tratar diferentes da biomedicina. Depois desse período de incentivo para um posicionamento radical, ou a biomedicina ou outra, começou-se a compreender que poderia haver uma ação complementar à biomedicina com a adoção de recursos terapêuticos e racionalidades que, pensando diferente, somassem às ações da biomedicina. Mais recentemente, a partir dos anos 2000, se busca uma integração de ações, em que outras racionalidades médicas entram no sistema do pensamento em saúde com igualdade.

Ainda temos mais um aspecto importante a compreender, o que distingue essas outras racionalidades e recursos terapêuticos da biomedicina. Podemos identificar vários aspectos e isso não se trata de um modismo. Chamar de alternativo deu a chance de se pensar que era um modismo. Consideremos que as Medicinas Ayurvédica e Tradicional Chinesa são tradicionais, existem pelo menos desde 3000 anos antes de Cristo. Elas foram constituídas a partir das tradições das suas culturas de origem. A homeopatia e a Antroposofia são elaborações datadas do século XIX e de países do continente europeu. O que distingue muito essas racionalidades da biomedicina é uma compreensão diferente do corpo humano e dos mecanismos de adoecimento e restabelecimento e cura. O corpo não é uma máquina constituída por partes que podem ser trocadas para manter o bom funcionamento. $\mathrm{O}$ corpo, para as racionalidades nãobiomédicas e os recursos terapêuticos associados, é um organismo vivo que tem a capacidade de se reorganizar, tratar-se, curar-se.

Os recursos terapêuticos contidos na PNPICS não possuem todos os elementos constitutivos de uma racionalidade. Em geral, apresentam formas de cuidar, terapêuticas e essas se pautam na compreensão que as ações dos recursos tratam fortalecer o que cada organismo já é e assim conquistar seu equilíbrio, seu bem estar. Deste modo, frases comumente repetidas na Terapia Comunitária, frases que são sínteses amplamente compreendidas pelos praticantes da TCI como: "quando a boca cala os órgãos falam, quando a boca fala os órgãos saram" ou "eu sou o doutor da minha dor" são concordantes com a compreensão das práticas integrativas e complementares em saúde. 
Desta forma a TCI tem um lugar de pertencimento nessa Política Nacional de Práticas Integrativas e Complementares em Saúde, e está contribuindo em um trabalho em rede intenso nesse momento sócio histórico planetário que estamos vivendo com o advento da pandemia, com as TCIs online, ofertadas pelo Brasil, América Latina e Europa. Nesse contexto em que precisamos nos isolar para proteger a nós e a quem amamos, as TCIs online surgiram como um estratégia rápida e eficaz, nos mantem conectados de forma virtual, porém traz para o real de nossa vidas o alivio de sofrimentos, de angustias, medos, construindo de maneira especial e sensível vínculos afetivos solidários.

Esse sensível que habita em nós humanos, que muitas vezes esquecemos ou nos distanciamos, um sensível que é expresso em palavras, olhares, gestos, aromas, sons, que está no simples, na delicadeza e no poder da gentileza.

$\mathrm{Na}$ terapia comunitária integrativa esse lugar do sensível tem destaque e somos convidados a permanecer e relembrar de nós mesmos, dos nossos valores, das heranças culturais, transgeracionais e, com o vínculo afetivo estabelecido com o grupo, transformar, encontrar outros significados para as dores que aprisionam nosso corpo e alma, temos a possibilidade de encontrar novas respostas para o velho que ainda nos habita.

A TCI possui uma associação, - ABRATECOM - Associação Brasileira de Terapia Comunitaria Integrativa ${ }^{7}$, desde 2004 que é autorizada pelo seu criador. É responsável por reconhecer, credenciar e legitimar terapeutas comunitários integrativos e instituições, polos que realizam Cursos/Capacitações em Terapia Comunitária Integrativa e Técnicas de Resgate da Autoestima - Cuidando do Cuidador. Somos mais de 30.500 terapeutas comunitários espalhados pelo mundo, formando uma grande rede humanitária de promoção de saúde mental.

Atualmente contamos com 42 Polos, distribuídos nos estados Amazonas, Bahia, Ceara, Goiás, Distrito Federal, Minas Gerais, Maranhão, Paraíba, Paraná, Pernambuco, Piauí, Rio de Janeiro, São Paulo, Sergipe, Santa Catarina, Rio Grande do Sul e nos países; Equador, Chile e Argentina.

Esse dossiê, conta com trabalhos que traduzem um panorama do impacto da TCI com sua diversidade de lugares e pessoas, um reconhecimento dessa estratégia de acolhimento ao sofrimento humano promoção de saúde metal e de qualidade de vida.

O percurso da leitura, inicia com um panorama atual da TCI com sua sistematização e valores ao longo desses 34 anos de existência, seguindo com contribuições de terapeutas

${ }^{7}$ Disponível em: https://abratecom.org.br/. Acesso em: 2 out. 2020. 
comunitários formadores, terapeutas comunitários pesquisadores e docentes atuantes com um fazer permanente e cuidadoso com a terapia comunitária integrativa.

São trabalhos que representam uma conectividade entre o saber científico e empírico, apresenta a TCI e o SER terapeuta comunitário em diversos contextos e populações, incluindo, crianças, jovens adultos e a bela e $3^{\mathrm{a}}$ idade.

Somos contemplados com autoras e autores com seus tons peculiares, com suas digitais contribuindo para a construção de um rico e fino tecido, um trabalho artesanal.

Admiração a Adalberto de Paula Barreto, Adriane Elizabeth Gamarra Gaete, André Luiz Pereira Silva, Angelina Vasconcellos de Chazarreta, Claudio Marlon da Silva, Deivisson Vianna, Djailton Pereira da Cunha, Dora Mariela Salcedo-Barrientos, Doralice Otaviano, Ellen de Souza Marquez, Etielle Talita Ribeiro Aguiar, Fernanda Cruz Vieira Ferreira, Graça Martini, Hulyana Pereira Pardinho, Josefa Emilia Lopes Ruiz, Juan José Leiva Olivencia, Jucelei Pascoal Boaretto, Jurema Walkiria Otaviano, Jussara Otaviano, Neusa Oliveira, Maria de Oliveira Ferreira Filha, Maria José Soares de Mendonça de Gois, Maria Vitória Silva Paiva, Marluce Tavares de Oliveira, Milene Zanoni da Silva, Noeli Kühl Svoboda, Olivier Gérard Angel Méric, Oscar Kenji Nihei, Pascal Jean, Roberth Steven Gutiérrez-Murillo, Rolando Lazarte, Rosaura Gutierrez Valero, Sabrina Stefanello, Sâmia Ferreira Leite, Sandriane A.Kalamar Martins, Silvana Camboim, Terezinha Zagotta Machado Pinezi, Walfrido Kühl Svoboda e Wellington Palmieri Donizete.

Um grupo especial, que contribui para a TCI no seu contínuo processo de construção e deixaram suas ricas evidencias registradas neste $1^{\circ}$ Dossiê temático bilíngue: o valor da Terapia Comunitária Integrativa (TCI) no Brasil e no mundo: possibilidades, impactos e perspectivas.

Por fim, agradecemos a todos que acreditaram nesse trabalho, especialmente a Prof. ${ }^{a}$ D.ra Luci Muzetti, supervisora do CENPE - Centro de Pesquisas da Infância e da AdolescênciaDante Moreira Leite - Unidade Auxiliar da Faculdade Ciências e Letras da UNESP Araraquara, também Polo de Formação em TCI, com seu permanente apoio e defesa dos trabalhos envolvidos com a TCI e com a Revista Temas em Educação.

E a José Anderson Santos Cruz, Editor Adjunto executivo dessa revista que com seu profissionalismo, perseverança e amor pelo que faz, contribuiu para uma produção coletiva, uma escrita inclusiva.

Valorizamos e admiramos toda a produção de conhecimento e do fazer da TCI inserida nessa Rede de Polos e de terapeutas comunitários espalhados pelo único lar que nós conhecemos... o pálido ponto azul (SAGAN, 2017). 


\section{Homenagem}

Ao Prof. Dr. Adalberto Barreto, por compartilhar seus conhecimentos, favorecer a construção contínua da Terapia Comunitária Integrativa e a ampliação da visão de mundo sensível do Ser terapeuta comunitário.

Á força da Rede de Polos da ABRATECOM - Associação Brasileira de Terapia Comunitária, com seus terapeutas formadores e alunos que compõem essa conexão em um fazer humanitário com a TCI.

Josefa Emilia Lopes Ruiz

Presidente da ABRATECOM

Gestão 2019-2021

\section{REFERÊNCIAS}

AUGUSTO, A. Introdução ao pensamento integrativo em medicina. In: BARRETO, A. L. (Org). Práticas integrativas em saúde: proposições teóricas e experiências na saúde e educação. Recife: Editora UFPE, 2014. p. 61-82.

BRASIL. Ministério da Saúde. Secretaria de Atenção à Saúde. Departamento de Atenção Básica. Política Nacional de Práticas Integrativas e Complementares no SUS - PNPICSUS. Brasília: Ministério da Saúde, 2006.

LUZ, M. T.; BARROS, N. F. (Orgs). Racionalidades médicas e práticas integrativas em saúde. Estudos teóricos e empíricos. Rio de Janeiro: CEPESC, IMS, UERJ, ABRASCO, 2012. $452 \mathrm{p}$.

NASCIMENTO, M. C. do et al. A categoria racionalidade médica e uma nova epistemologia em saúde. Ciênc. saúde coletiva, Rio de Janeiro, v. 18, n. 12, p. 3595-3604, dez. 2013. Disponível em: https://www.scielo.br/pdf/csc/v18n12/a16v18n12.pdf. Acesso em: 20 jul. 2020.

SAGAN, C. Secretaria de Educação. Departamento de Educação e Trabalho. O pálido ponto azul. Curitiba: Secretaria de Educação, 2017. Disponível em:

http://www.educadores.diaadia.pr.gov.br/arquivos/File/formacao_acao/2semestre2017/fa2017 _sustentabilidade_DET_anexo1.pdf3. Acesso em: 20 jul. 2020. 


\section{Como referenciar}

SILVA FRANCO, Anamélia Lins e; SILVA, Milene Zanoni da; LOPES RUIZ, Josefa Emilia; MURCIA, Morgana; DE SOUZA, Taisa Borges; MUZZETI, Luci Regina. O valor da Terapia Comunitária Integrativa (TCI) no Brasil e no mundo: possibilidades, impactos e perspectivas. Temas em Educ. e Saúde, Araraquara, v. 16, n. esp. 1, p. 232-238, set., 2020. e-ISSN 25263471. DOI: https://doi.org/10.26673/tes.v16iesp.1.14303

Enviado: $20 / 05 / 2020$

Revisiones necesarias: 30/05/2020

Aprobado: $25 / 08 / 2020$

Publicado: $30 / 09 / 2020$ 